\title{
Psychiatric Morbidity among Children and Adolescents Attending Psychiatric Clinic of a Tertiary Hospital
}

\author{
Bhaskkar Sharma, ${ }^{1}$ Rajesh Shrestha, ${ }^{1}$ \\ 'Department of Psychiatry, Lumbini medical College and Teaching Hospital, Palpa, Nepal.
}

\begin{abstract}
Introduction

A variety of psychiatric manifestations can be seen in children and adolescents below the age of 19 years. This study aims to examine the socio-demographic, morbidity profiles, and clinical correlates of child and adolescent patients attending the psychiatry out-patient clinic of Lumbini Medical College and Teaching Hospital (LMCTH).
\end{abstract}

\section{Methods}

It was an observational, cross-section study involving case record analysis of all children and adolescent patients attending the psychiatry out-patient clinic between December 1, 2018 to November 30, 2019 in LMCTH, Nepal. Socio-demographic and clinical data were entered into computer software and analysed.

\section{Results}

One hundred and forty cases fulfilling inclusion criteria were included in the study. There were $96(68.6 \%)$ females and $44(31.4 \%)$ males. Majority of the patients were from 16-19 years agegroup. Cases from urban areas predominated the picture. Most common psychiatric diagnosis was conversion disorder $(29,20.7 \%)$ followed by depressive disorder ( 25 or $17.9 \%)$ and anxiety disorder (14, 10\%). Majority of females had conversion disorder (25 or $26 \%$ ) followed by seizure disorder $(23,24 \%)$ and depressive disorder $(15,15.6 \%)$ whereas majority of males had equal count of depressive disorder and seizure disorder $(10,22.7 \%)$ followed by anxiety disorder $(7$, $15.9 \%)$.

\section{Conclusions}

Psychiatric illness was most common in children and adolescents in the age group 16-19 years, followed by 11-15 years age-group. They were more common in female sex, and slightly higher in those from urban background. Common psychiatric diagnoses were conversion disorder followed by depressive disorder and anxiety disorder.

Keywords: adolescents; children; psychiatric morbidity; socio-demography.

Correspondance: Dr. Bhaskkar Sharma, Department of Psychiatry, Lumbini Medical College and Teaching Hospital, Tansen, Nepal. Email: vasker63@yahoo.com. Phone: +977-9844758742. 


\section{INTRODUCTION}

WHO statistics reveals that the prevalence of disabling mental illness among children and adolescence attending health care centres range between $20-30 \%$ in urban areas and $13-18 \%$ in rural areas. ${ }^{1}$ Various studies from developing countries including Nepal and India show that a significant percentage (7-35\%) of the paediatric population suffers from mental illness. ${ }^{2-6}$ It is estimated that $10-20 \%$ of children and adolescents are affected annually by psychiatric problems and their psychiatric morbidity accounts for five of the 10 leading causes of disability for those aged five years and above. It has been found that mental and psychiatric services for children lag behind those for adults in developing countries. ${ }^{7-11}$ Studies completed at various centres in Nepal show that a great majority of children and adolescents visit other setting of help-seeking before coming to a psychiatric service for different psychological problems. ${ }^{4,6}$ This study aims to examine the sociodemographic, morbidity profiles, and clinical correlates of child and adolescent patients attending the psychiatry out-patient clinic of Lumbini Medical College and Teaching Hospital (LMCTH). Information regarding the morbidity profiles of these young patients would help to define needs and priorities.

\section{METHODS}

This was an observational, cross-sectional study conducted at the psychiatric out-patient clinic of LMCTH, Nepal. Ethical clearance was obtained from Institutional Review Committee (IRC) of the college. The primary data were stored in the case-records of the patients in the clinic. Secondary data were collected from those records. The study was conducted from Dec $1^{\text {st }}$ 2018 to Nov30 2019.

All the patients below 19 years of age visiting the psychiatric clinic from December 1, 2018 to
November 30, 2019 were included in the study. Cases with incomplete data in the record were excluded. The case-records were reviewed and information regarding socio-demographic characteristic (eg age, gender, religion, domicile) and clinical details was recorded on a proforma designed by the authors in Microsoft Excel 2007. The entered data were double checked for any errors. Data were imported into the Statistical Package for Social Sciences (SPSS) version 16 and coding was done. Results were calculated and presented in form of frequency and percentages. Cross-tabulation of categorical data was done presented in tabular form.

\section{RESULTS}

A total of 140 child and adolescent patients had attended the psychiatry clinic during the period in review. Of those, $96(68.6 \%)$ were females and the rest $44(31.4 \%)$ were males. The age distribution of the study subjects is presented in Table 1 which shows that children with elderly age were more frequent.

\begin{tabular}{|c|r|r|}
\hline \multicolumn{3}{|c|}{ Table 1. Age distribution of the study subjects } \\
\hline Age in Years & \multicolumn{1}{|c|}{ Frequency } & \multicolumn{1}{|c|}{ Percent } \\
\hline $0-5$ & 1 & 0.7 \\
\hline $6-10$ & 8 & 5.71 \\
\hline $11-15$ & 51 & 36.42 \\
\hline $16-19$ & 80 & 57.14 \\
\hline Total & 140 & 100 \\
\hline
\end{tabular}

Locality of the subjects is presented in Table 2 which shows children from urban background were slightly higher in numbers as compared to those from rural places.

\begin{tabular}{|c|r|r|}
\hline \multicolumn{3}{|c|}{ Table 2. Locality of the study subjects } \\
\hline Locality & Frequency & \multicolumn{1}{c|}{ Percent } \\
\hline Rural & 67 & 47.9 \\
\hline Urban & 73 & 52.1 \\
\hline Total & 140 & 100 \\
\hline
\end{tabular}


Psychiatric diagnosis of the study subjects is shown in Table 3 which demonstrate that conversion disorder was the most common diagnosis followed by depressive disorders, anxiety disorders and others. Seizure disorder was the most common non-psychiatric illness present in the study population.

Table 3. Psychiatric diagnosis of the study subjects

\begin{tabular}{|l|c|c|}
\hline \multicolumn{1}{|c|}{ Psychiatric diagnosis } & Frequency & Percent \\
\hline Conversion Disorder & 29 & 20.7 \\
\hline Depressive Disorder & 25 & 17.9 \\
\hline Anxiety Disorder & 14 & 10 \\
\hline Somatoform Disorder & 6 & 4.3 \\
\hline Schizophrenia & 5 & 3.6 \\
\hline Acute Stress Reaction & 3 & 2.1 \\
\hline Psychosis NOS & 2 & 1.4 \\
\hline Recurrent Depressive disorder & 2 & 1.4 \\
\hline Post Partum Psychosis & 2 & 1.4 \\
\hline Mixed Anxiety Depression & 2 & 1.4 \\
\hline Deliberate Self Harm & 2 & 1.4 \\
\hline Manic Episode(F31) & 1 & 0.7 \\
\hline Mixed headache & 1 & 0.7 \\
\hline Night Terror & 1 & 0.7 \\
\hline Alcohol Dependent Syndrome & 1 & 0.7 \\
\hline Tension Headache & 1 & 0.7 \\
\hline Post-Traumatic Stress Disorder & 1 & 0.7 \\
\hline Psychiatric Disorder NOS(F99) & 1 & 0.7 \\
\hline Cannabis induced Psychosis & 1 & 0.7 \\
\hline Other non-psychiatric illness: & & \\
\hline Seizure Disorder & 33 & 23.6 \\
\hline Migraine Headache & 3 & 2.1 \\
\hline Mental Retardation (MR) & 1 & 0.7 \\
\hline Observation with admission & 1 & 0.7 \\
\hline MR with seizure disorder & 1 & 0.7 \\
\hline Thyroid Disorder & 1 & 0.7 \\
\hline Total & & 100 \\
\hline
\end{tabular}

Table 4 compares the psychiatric diagnosis between males and females. It shows conversion and depressive disorders are more common in females as compared to males. Similarly, seizure disorder which is a non-psychiatric disorder was also more common in females. The details are presented in the table.

\begin{tabular}{|c|c|c|c|}
\hline \multirow[b]{2}{*}{ ICD-10 Psychiatric Diagnosis } & \multicolumn{2}{|c|}{ Gender } & \multirow{2}{*}{$\begin{array}{l}\text { Total } \\
\mathrm{n}(\%)^{*}\end{array}$} \\
\hline & $\begin{array}{c}\text { Female } n \\
(\%)^{*}\end{array}$ & $\begin{array}{c}\text { Male n } \\
(\%)^{*}\end{array}$ & \\
\hline Conversion Disorder & $25(26)$ & $4(9.1)$ & $29(29.7)$ \\
\hline Depressive Disorder & $15(15.6)$ & $10(22.7)$ & $25(17.9)$ \\
\hline Anxiety Disorder & $7(7.3)$ & $7(15.9)$ & $14(10)$ \\
\hline Somatoform Disorder & $5(5.2)$ & $1(2.3)$ & 614.30 \\
\hline Schizophrenia & $4(4.2)$ & $1(2.3)$ & $5(3.6)$ \\
\hline Acute Stress Reaction & $1(1.04)$ & $2(4.5)$ & $3(2.1)$ \\
\hline Deliberate Self Harm & 0 & $2(4.5)$ & $2(1.4)$ \\
\hline Mixed Anxiety Depression & $2(2.1)$ & 0 & $2(1.4)$ \\
\hline Post Traumatic Stress Disorder & $2(2.08)$ & 0 & $2(1.4)$ \\
\hline Alcohol Dependent Syndrome & 0 & $1(2.3)$ & $1(0.7)$ \\
\hline Cannabis induced Psychosis & 0 & $1(2.3)$ & $1(0.7)$ \\
\hline Manic Episode (F31) & 0 & $1(2.3)$ & $1(0.7)$ \\
\hline Psychosis NOS & 0 & $2(4.5)$ & $2(1.4)$ \\
\hline Recurrent Depressive disorder & $2(2.1)$ & 0 & $2(1.4)$ \\
\hline Mixed headache & 0 & $1(2.3)$ & $1(0.7)$ \\
\hline Night Terror & $1(1.04)$ & 0 & $1(0.7)$ \\
\hline Psychiatric Dsorder NOS(F99) & $1(1.04)$ & 0 & $1(0.7)$ \\
\hline Tension Headache & $1(1.04)$ & 0 & $1(0.7)$ \\
\hline Post Partum Psychosis & $1(1.04)$ & 0 & $1(0.7)$ \\
\hline \multicolumn{4}{|l|}{ Other non-psychiatric diagnosis } \\
\hline Seizure Disorder & $23(24)$ & $10(22.7)$ & $33(23.6)$ \\
\hline Migraine Headache & $3(3.1)$ & 0 & $3(2.1)$ \\
\hline Mental Retardation & 0 & $1(2.3)$ & $1(0.7)$ \\
\hline MR with seizure disorder & $1(1.04)$ & 0 & $1(0.7)$ \\
\hline Observation with admission & $1(1.04)$ & 0 & $1(0.7)$ \\
\hline Thyroid Disorder & $1(1.04)$ & 0 & $1(0.7)$ \\
\hline Total & $96(100)$ & $44(100)$ & 140 \\
\hline
\end{tabular}

*Among gender 


\section{DISCUSSION}

Psychiatric diseases were most common in children and adolescents in 16-19 years agegroup followed by 11-15 years age-group and they were more common in females. There were fewer patients of younger ages. It indicates the need of raising awareness about psychological problems of this age groups. The observation may help in better planning of mental health services, with special focus towards these vulnerable age groups.

The observed findings of female dominance in this study was similar to various other studies. This finding was similar to the findings of Risal A which reported that $66.7 \%$ of the total study population was in the age group of 15-18 years with female dominance. ${ }^{12}$ Patients from urban background were slightly more than those from rural background. Shakya Dr also found that patients from urban areas were more prone to psychiatric illness. ${ }^{6}$ This may be due to less frustration tolerance and more stressful life in urban areas.

In this study the greatest number of patients were of seizure disorder which was a nonpsychiatric diagnosis and was more common in female patients. This finding is new may be because of the disorderfirstly came topsychiatry OPD in our hospital rather than the Paediatric OPD. Then came conversion disorder which was maximum in female patients. Higher prevalence of epilepsy in child and adolescents was supported by studies from $\operatorname{Nepal}(6,12)$ and that of dissociative disorder by studies from both of Nepal $(12,13)$ and India(14). This may be related to the possibilities that Nepali culture discourages direct expression of emotional distress as a result of which physical symptoms are a common way of expressing psychological distress. Next common was depressive disorder and this was also more common in females. Mental retardation was very less in our study (only 2 cases out of 140). This is quite paradox to the study done by Chaudhary CS in which the total cases of mental retardation were $10.5 \%{ }^{15}$ This may be due to most of the cases being primarily seen by the Paediatric department in our hospital. One interesting finding is that there were no cases of conduct disorder, ADHD, Autism, enuresis, somnambulism, trichotillomania, and tic disorder which might be due to nonreferral of the cases from Paediatric OPD.

There were some limitations in the study. Sample size is small. Study is confined to a tertiary hospital, which may not necessarily represent the general population of the country. Most of the case record were found to have incomplete data about educational qualification, socio-economic class, religion and hence could not be compared. Further community-based surveys in a larger scale with appropriate sample size are needed to find out the depth of the psychiatric problems in children.

\section{CONCLUSIONS}

Psychiatric illness was most common in children and adolescents in the age group 16-19 years, followed by 11-15 years agegroup. They were more common in female sex, and slightly higher in those from urban background. Commonest psychiatric diagnoses were conversion disorder followed by depressive disorder and anxiety disorder. Seizure disorder was the most common nonpsychiatric diagnosis. 


\section{REFERENCES}

1. Hassan ZK. Children mental health problems and prospects using primary health care. Pak J Child Mental Health 1991;2:90-101.

2. Shrestha DM. Neuropsychiatric problems in children attending a general psychiatric clinic in Nepal . J Nepal Peadiatric Soc 1986;5:97-10.

3. Chadda RK and Saurabh . Pattern of Psychiatric Morbidity in Children Attending a General Psychiatric Unit. Indian J Pediatr 1994;61:281-85.

4. Regmi SK, Nepal MK, Khalid A , Sinha UK, et al. A study of children \& adolescents attending the child guidance clinic of a general hospital. Nepalese Journal of Psychiatry 2000;1:90-7.

5. Srinath S, Girimaji SC, Gururaj G, et al. Epidemiological study of child \& adolescent psychiatric disorders in urban and rural areas of Bangalore, India. Indian J Med Res 2005;122:67-79.

6. Shakya DR. Psychiatric Morbidity Profiles of Child and Adolescent Psychiatry Out-Patients in a TertiaryCare Hospital. J Nepal Paediatr Soc 2010;30:79-84.

7. Murray CJL, Lopez AD, editors. The global burden of disease . Cambridge MA: Harvard University Press on behalf of the World Health Organization \& World Bank. 1996: 201-46.

8. Sawyer MG, Arney FM, Baghurst JJ, et al. The mental health of young people in Australia: key findings from the child and adolescent component of the national survey of mental health and wellbeing. Aust NZJ Psychiatry 2001;35:806-14
9. Mc Kelvey RS, Sang DL, Baldassar L, Davies L , NRoberts L, Cutler N . The prevalence of psychiatric disorders among Vietnamese children and adolescents. Medical Journal of Australia 2002; 17:410-3

10. Sourander A, Turunen MM. Psychiatric hospital care among children and adolescents in Finland: a nation wide register study. Soc Psychiatry Epidemiology 1999; 34:105-10

11. Eapen V, Swadi H, Sabri S, Abou-Saleir M. Childhood behavioural disturbance in a community sample in Al-Ain, United Arab Emirates. East Mediterr Health J 2001;7:428-34.

12. Risal A and Sharma PP. Psychiatric illness in the paediatric population presenting to a psychiatry clinic in a tertiary care centre. Kathmandu University Medical J 2010;9(32):375-81.

13. Chapagai M,Dangol KM,Tulachan P.A study of psychiatry morbidity amongst children attending a child guidance clinic at a tertiary level teaching hospital in Nepal.Journal of Nobel Medical College.2013;2(1:9):55-63.

14.Maan CG,Munnawar HMS,Hiramani N,Lenin RK.Psychiatric morbidity profiles of child and adolescent patients attending the regional Institute of Medical sciences,Imphal. IOSR Journal of Dental and Medical sciences.2014;13(12):47-51.

15. Col S Chaudhury (Retd), Col PL Prasad, R Zacharias, Lt Col T Madhusudan, Lt Col R Saini. Psychiatric Morbidity Pattern in a Child Guidance Clinic. Medical Journal Armed Forces India, April 2007; 63(2)144-146.

Citation: Sharma B, Shrestha R. Psychiatric Morbidity among Children and Adolescents Attending Psychiatric Clinic of a Tertiary Hospital. JCMS Nepal. 2021 ; 17(2); 124-28. 